\title{
Drug trafficking in the Golden Triangle: The Myanmar problem and ASEAN effectiveness.
}

\author{
Nathan Harper \\ Undergraduate Student of International Relations Department at Curtin University. \\ nathanharper@iinet.net.au \\ Nathan Tempra \\ Undergraduate Student of International Relations Department at Murdoch University. \\ nathantem91@gmail.com
}

\begin{abstract}
This essay explores the issue of drug trafficking and production in Myanmar to understand the extent of damage this problematic situation has on the South East Asian region and to discuss what steps are being taken by institutions to stem the proliferation of narcotics such as heroin and amphetamines. Myanmar's turbulent political history and unique geographical position have been explained to garner knowledge on why drug trafficking and production are so closely associated with the nation. The policymaking efforts of the Association of South East Asian Nations (ASEAN) to combat drug trafficking and production in the region have so far been plagued by obstructions such as internal corruption, a lack of multilateral cooperation and insufficient resources. These barriers combine to create policy that it is aligned closer to empty rhetoric than actual physical implementation. The ASEAN and China Cooperative Operations in Response to Dangerous Drugs (ACCORD) agreement has shown signs of a changing tide toward effective policymaking, due mainly to China stepping up to the plate of regional leadership. This essay recommends that in order to successfully fight drug trafficking and production, ASEAN need to establish more realistic and achievable goals with an emphasis on rehabilitation rather than punishment. Furthermore, compliance mechanisms should be put in place by ASEAN so that countries such as Myanmar, who often deviate from the status quo of drug policy, will be reprimanded for doing so in the future. Thus, creating an environment of multilateral cooperation, togetherness and consistency in relation to combatting the illegal drug trafficking and production trade.
\end{abstract}


The golden triangle is one of the world's premier opium and methamphetamine trafficking destinations; Myanmar dominates the production and trafficking of opiates and is heavily involved in the production and trafficking of Amphetamine Type Substances (hereafter ATS). Myanmar faces an inability to adequately curtail drug production due to a myriad of political and social factors and this is only further problematic in light of selective policing policies against drug users and inefficiency in seizures and poppy eradication. The drug trade is inexorably tied to the geopolitical realities of the region and everything from regional to international (Sino-US) strategic considerations both limit progress to and prolong the mechanisms of drug production. ASEAN as the premier regional grouping which has made itself committed to curtailing drug production in the region since 1976 has faced consistent shortcomings due to the predominately rhetorical nature of its attempts to bind states together to attack the problem. Internal corruption and a lack of resources is also a significant roadblock facing the prospect of ASEAN's ability to push forward meaningful legislative action towards curtailing the production and trafficking of drugs within the golden triangle.

The golden triangle is a 150,000 square mile mountainous region which is home to Myanmar, Thailand and Laos. The proliferation of drug production and trafficking over the golden triangle, especially in regards to the production of heroin and methamphetamines can be attributed, at least somewhat largely to the state of Myanmar. Myanmar is the world's second largest producer of heroin behind Afghanistan and accounted for 92 per cent of the golden triangles production at the turn of the $21^{\text {st }}$ century (Chalk; 2000, P.92) and is heavily involved in the production and trafficking of methamphetamine. In 'Methods of madness: Methamphetamines and the Golden Triangle', Lintner and Black argue the political problems and ethnic conflicts in Myanmar for the rise of amphetamine production and distribution (Lintner and Black; 2009). A large portion of the heroin that is transported from the golden triangle goes through the Myanmar-Thailand border; Thailand shares a 2,400 km border with Myanmar which is porous and largely demarcated which leads to insufficiency in attempts to supress drug movement (Emmers; 2007, P. 511). As opium cultivation has become more controlled in the Golden Triangle (minus Myanmar), Chris Lytelleton argues that ATS (amphetamine type stimulants) have become the "drug of choice" for producers and 
traffickers in Northern Thailand, North-western Laos and North-eastern Myanmar (Lyttleton; 2004, P. 910).

Chin argues that the drug trade is "an important part of the politics of Southeast Asia"; it is important to underscore the geopolitical considerations which allow the trafficking of narcotics from Myanmar across the golden triangle to remain relatively unpatrolled to move towards solutions for its eradication. The Burmese government is intrinsically involved in the production of heroin within in its borders; so too, high ranking military officials are said to be heavily involved in the methamphetamine business (Ball; 1999, P.6). There are very few channels for high streamline profits within the country and its allowance of production of heroin in the Wa state, for example, is met with strategic considerations; the Wa state is left alone to traffic and produce drugs not only because economically it serves the Myanmar state but it also allows the government to focus on other numerous contending political forces. Other strategic considerations can be argued to come from the Importance of the Wa state as a buffer state against Thai armed forces which pleases the Myanmar government having a pacified and highly armed state between Yangon and its neighbours. Chin argues that in "the long history of animosities" between Myanmar and Thailand, the Wa and the Shan were often used as "buffers" during hostilities and their actions over or underplayed by the governments to achieve political goals (Ibid; P. 235).

The realities of drug production in Myanmar have much to do with the political situation; the post 1962 state, dominated by the Tatmadaw military Junta, has been far from a pluralistic society which has an ever evolving civil war with minority ethnic groups and the absence of concrete rule of law which leaves "continuous strife" and the heroin flowing (Lintner; 1994, P. 331-335). Ongoing political conflicts exacerbate the already thin reach of the government to provide adequate social services such as drug prevention and education programmes, along with health care and aid to village groups such as the Wa who rely on drug production for state building and lifelines. So too the ability of the Myanmar government to deal with ongoing political conflicts, maintain legitimacy and establish adequate rule of law leaves them little resources or want to deal with what remains a lucrative venture for the state apparatus. Whilst looking at the internal systematic factors that lead to the accommodation of drug producers and traffickers within Myanmar, it is important to note the role of China, Thailand, the importance of its economic openings under Deng Xiaoping and Sino-US relations. 
China's opening of their doors to trade after the coup that ended the power of the Gang of Four was an enabler to the drug trade through Deng's speech acts encouraging acquisition of wealth through China's open door policy. After China withdrew its support from the Burmese communist party, many Wa leaders took to distancing themselves from the communist party and developing their societies through the drug trade (Lintner; 1990). Thailand's linkages with Myanmar, more specifically Northern Thailand, alongside the Yunnan province in China bare special mention in the proliferation of heroin and amphetamines from the Wa state due to their close economic, social and cultural connections with the heavy production regions of the Wa area. Myanmar is also one of the only South East Asian states that is not aligned with Washington and instead has cordial relations with Beijing; this is a limitation that can be argued to make Beijing reticent to come down harshly upon the exchanges between the Wa, Shan etc. and the Yunnan provinces in fear of losing a valuable regional ally.

To grasp the scope of Myanmar's drug related issues, it is valuable to analyse how the adoption of repressive and harsh drug policies have impacted its society. Currently, the law, based primarily on the 1993 Narcotics Drugs and Psychotropic Substance Law, criminalises drug use, possession, cultivation, production, and trafficking (Kramer; 2007, P.13). Yet it also imposes penalties on drug users who fail to register themselves as such; many have been prosecuted under this law (Section 15) (ibid; 2007, P.13). This has led to a disturbing situation whereby many drug users have been jailed for minor offences whilst others who remain free fear that drug rehabilitation programs are merely a guise to conviction. Thus, Myanmar faces an unfortunate juxtaposition of overpopulated prisons and underpopulated, ineffectual rehabilitation facilities (ibid; 2007, P.14). It is appropriate to note that when addressing an issue such as illicit drugs, empirical analysis can be rather difficult. As respondents who have the most information are often unwilling to provide it due to personal security concerns, especially in Myanmar, whereby freedom of speech regarding personal drug use has often led to incarceration ( $\mathrm{Su} ; 2015$, P.73). With regard to drug trafficking for example, Myanmar statistically has a very low rate of seizure which does not reflect its status as South East Asia's leading opium poppy and ATS producer (Emmers; 2007, 510). Therefore, academic discussion of this topic utilises trends and correlations rather than pure statistical evidence, which is either difficult to attain or skewed to present a certain perspective (Su; 2015, P.73). 
As a member of ASEAN, Myanmar is part of the pledge to free the region of drug use by 2015 . This target was recognised as insurmountable and as such, ASEAN redefined "drug free" to a "significant reduction in drug consumption, production, and trafficking (Kramer; 2007, P.14)". In addition, Myanmar has postponed their deadline to achieve this to 2019. With that date creeping closer, headway to successful drug reduction is far from sight. Instead, Myanmar has increased adoption of repressive and counter-intuitive activities including the eradication of opium fields, a method that has been proven to displace crops of local farmers and in some cases, increase levels of opium cultivation, and questionable arrests of drug users (Ibid; P.13). However, the future is beginning to brighten, as Myanmar is looking outward internationally to understand how to best reform their outdated drug policies. It seems Myanmar would benefit heavily from international condemnation, from agencies such as the UN, of the ineffectual and counterproductive nature of ASEAN's zero tolerance "drug free" deadlines, which at its core presents an unachievable target that forces Myanmar into rushing a process that is deeply intricate and fragile. Thus, ASEAN should look to create more realistic goals founded in rural development and proper rehabilitation that aims to enhance the quality of life of affected communities.

In the context of ASEAN, the issue of drug trafficking was first brought to attention in 1976 at the first ASEAN Summit of Heads of State and Government held in Bali (ASEAN; 1976). Yet due to a lack of cooperative activity, distinct leadership, and a mainly rhetorical dialogue, the steps toward effective action did not take place until the late 1990's (Emmers; 2007, P.513). An active China and the addition of Cambodia, Vietnam, Myanmar, and Laos into ASEAN spurred new activity, characterised by the foundation of the ASEAN and China Cooperative Operations in Response to Dangerous Drugs (ACCORD) in 2000 (ibid; 2007, P.512). ACCORD demonstrates the strongest attempt at developing a multilateral cooperative framework to address the issue of illicit drugs that the region has seen to date (ACCORD; 2000). China's motivation to become a regional leader by establishing a coherent regional structure has somewhat filled the leadership void that previously plagued ASEAN (ibid; 2007, P.513). However, it can be argued that roadblocks in the form of corruption, domestic pressure, lack of resources and internal politics have so far delayed the prospect of an effective anti-drug regime under the sphere of ASEAN (ibid; 2007, P.514).

Prior to this, efforts by ASEAN to stem the problematic drug trade had already begun. In 1994, the ASEAN Plan of Action on Drug Abuse Control utilised four pillars of 
cooperative implementation; namely: treatment and rehabilitation, enforcement and legislation, prevention and information, and training and research, to develop ten projects specifically relating to the control and reduction of the illegal drug trade (ASEAN; 1994). Unfortunately however, these declarations never translated into reality. Without an obvious leader, the Philippines and Manila (who lead the initiative) were unable to apply enough pressure for countries such as Myanmar and Laos to act (Emmers; 2007, P.513). With this in mind, it is evident that prior to ACCORD, ASEAN without the leadership of China fell short of what it intended to achieve due to an inability to efficiently cooperate with one another at the multilateral level.

When discussing the ACCORD, one aspect stands out as obvious, the commanding power of Chinese leadership. Without China, ASEAN's drug reduction strategies have historically fallen short of expectation, with no single country arising as leader theoretically valuable and practical policies have fallen by the wayside. This is not to say that ACCORD has been successful, as it still is far from that. However, it represents a concrete mechanism to combat the issue of drugs with the intention of doing so through multilateral cooperation. When addressing its shortfalls, the primary issue is regional nations limiting their cooperation to national and bilateral levels, a fundamental problem that ASEAN nations must overcome in order to achieve the goals they plan on achieving (ibid; 2007, P.514). Arguably the biggest impediment to success of the ACCORD is the lack of compliance mechanisms; nations are not met with recourse if they do not adhere to expectation (ibid; 2007, P.514). Therefore, in order for ASEAN and China to successfully reduce and eventually halt the production, trafficking, and consumption of illicit drugs in their region they must first work together multilaterally and second adopt mechanisms that encourage nations to act and comply with ACCORD's policies.

The non-traditional security threat of illicit drugs, particularly in relation to the production, trafficking, and consumption of heroin and amphetamine based substances (ATS), represents a pivotal issue for the countries belonging to the Golden Triangle and for the wider South East Asian region. Political unrest in Myanmar has fuelled the proliferation of this issue; scarce resources, lack of government support, and prohibitive drug policies all combine to constrain mechanisms for advancement toward significant reduction of illicit drugs. Myanmar's continues to be the worlds second largest opium producer and is becoming increasingly involved in the trafficking of ATS. The Wa region in the Shan State is the 
regions primary contributor to both drug production and trafficking. Myanmar's shared border with Northern Thailand has motivated Bangkok to push for more realistic strategies to combat the issue; however, absence of support from ASEAN multilaterally has diminished the possibility of on the ground drug reduction efforts. The inclusion of China in the ACCORD has been beneficial, whilst the ACCORD still lacks compliance mechanisms; the primacy of China's leadership has instilled newfound cooperation, albeit at this stage largely at the bilateral level. Moving forward, ASEAN and China must cooperate with one another multilaterally through ACCORD to achieve consistent and realistic drug reduction policies and physical implementation. 


\section{BIBLIOGRAPHY}

ACCORD. 2000. "ASEAN and China Cooperative Operations in Response to Dangerous Drugs (ACCORD)'”. Bangkok, Thailand, 13 October. http://www.aseansec.org/645.htm

ASEAN. 1976. "Declaration of ASEAN Concord". Bali, Indonesia, 24 February. http://www.aseansec.org/1216.htm

ASEAN. 1994. "Plan of Action on Drug Abuse Control, 17th Meeting of the ASEAN Senior Officials on Drug Matters (ASOD)”. October. http://www.aseansec.org/5735.htm

Ball, D. 1999.. Burma and drugs: the regime's complicity in the global drug trade. No. 336. Strategic and Defence Studies Centre, Australian National University. P.6

Chalk, P. 2000."Southeast Asia and the Golden Triangle's heroin trade: Threat and response." Studies in Conflict and Terrorism 23, no. 2: P. 92

Emmers, R. 2007. "International regime-building in ASEAN: Cooperation against the illicit trafficking and abuse of drugs." Contemporary Southeast Asia: P. 511.

Kramer, T. 2017. "The Current State of Counternarcotics Policy and Drug Reform Debates in Myanmar." Journal of Drug Policy Analysis 10: P. 13-14.

Lintner, B, and Michael Black. 2009. "Merchants of madness: The methamphetamine explosion in the Golden Triangle". Silkworm Books.

Lintner, Bl. The rise and fall of the Communist Party of Burma (CPB). No. 6. SEAP Publications, 1990.

Lintner, B1. 1999. Burma in revolt: Opium and insurgency since 1948. 2nd ed. Chiang Mai, Thailand: Silkworm Books. P. 331-335. 
Lyttleton, C. 2004. Relative pleasures: Drugs, development and modern dependencies in asia's golden triangle. Development and Change 35 (5): P. 910.

$\mathrm{Su}$, X. 2015. "Nontraditional security and China's transnational narcotics control in northern Laos and Myanmar." Political Geography 48: P.73. 